\title{
Effect of the number of peak expiratory flow readings per day on the estimation of diurnal variation
}

\author{
P F G Gannon, D T Newton, C F A Pantin, P S Burge
}

Occupational Lung

Disease Unit,

Birmingham

Heartlands Hospital, Birmingham B9 5ST, UK

P S Burge

Industrial and Community Health Research Centre, Keele University School of Post

Graduate Medicine, North Staffordshire Hospital, Stoke on

Trent ST4 7NY, UK D T Newton

C F A Pantin

Correspondence to: Dr P S Burge.

Received 29 March 1996 Returned to authors 21 June 1996

Revised version received 23 March 1998

Accepted for publication 22 April 1998
P F G Gannon

\begin{abstract}
Background-The number of peak expiratory flow (PEF) readings required per day to assess diurnal variation accurately is not known; published studies have used between two and seven PEF readings per day. This study compares the diurnal variation calculated using 2-10 PEF readings per day.

Methods-All days with 10 readings were selected from a database of PEF records. For each day, diurnal variations calculated using 2-9 of the readings available were compared with that calculated using the full 10 PEF readings. Diurnal variation calculated using all 10 readings was taken as the true diurnal variation. When less than 10 readings were used the readings were evenly spaced over waking hours. Diurnal variation was calculated as maximum - minimum/predicted.

Results-Two hundred and 25 days with 10 readings per day were selected from PEF records provided by 63 individuals. When only two PEF readings per day were used, the limits of agreement suggested a possible underestimate of true diurnal variation, calculated using all 10 readings, of $1.23-15.10 \%$. The possible underestimate fell to $0.27-3.96 \%$ when calculated using four evenly spaced readings. Analysis of the timing of the highest PEF reading of the day was undertaken for rest and work days. This showed a mean (SD) timing of 13:56 (4:56 hours) for rest days and 11:47 (5:59 hours) for work days.
\end{abstract}

Table 1 Spacing of peak expiratory flow (PEF) readings when fewer than 10 were used

\begin{tabular}{llll}
\hline $\begin{array}{l}\text { No. of PEF } \\
\text { readings used }\end{array}$ & Spacing of PEF readings used & $\begin{array}{l}\text { Mean difference in } \\
\text { diurnal variation }\end{array}$ & $\begin{array}{l}\text { Limits of agreement } \\
\text { of diurnal variation }\end{array}$ \\
\hline 2 & wake 1,10 bed & -2.80 & 1.57 to -12.3 \\
3 & wake $1,6,10$ bed & -1.72 & 1.86 to -5.53 \\
4 & wake $1,3,7,10$ bed & -1.30 & 1.57 to -2.66 \\
5 & wake $1,3,5,8,10$ bed & -1.20 & 1.54 to -2.21 \\
6 & wake $1,3,4,5,8,10$ bed & -1.14 & 1.46 to -1.91 \\
7 & wake $1,3,4,5,7,8,10$ bed & -1.08 & 1.32 to -1.53 \\
8 & wake $1,3,4,5,6,7,8,10$ bed & -1.06 & 1.28 to -1.43 \\
9 & wake $1,2,3,4,5,6,7,8,10$ bed & -1.02 & 1.14 to -1.18
\end{tabular}

PEF readings were performed two hourly over waking hours. Reading 1 represents the reading taken on waking, reading 10 represents the reading taken on retiring to bed, and readings 2-9 represent those readings performed at approximately two hourly intervals throughout the day. Mean underestimates of true diurnal variation and limits of possible underestimates of diurnal variation are also shown.
Conclusions-Clinically significant underestimates of true diurnal variation may be seen when only small numbers of PEF readings per day are used in its calculation. At and above four readings the results suggest that the underestimate becomes increasingly insignificant in terms of the diagnosis and treatment of asthma. Analysis of the timing of the highest PEF reading of the day showed a wide variation, precluding the ability to capture the true diurnal variation with just two or three carefully timed PEF readings per day. The authors suggests that at least four readings per day should be performed, evenly spaced during waking hours, to obtain an accurate assessment of diurnal variation in PEF.

(Thorax 1998;53:790-792)

Keywords: diurnal variation; peak expiratory flow; asthma

The number of PEF readings per day required to assess the degree of circadian (24 hour) variation in PEF accurately is not known. Clinically, diurnal (daytime) variation in PEF is used to assess the degree of airway lability. A review of published work shows a wide range in the number of PEF readings used to assess diurnal variation. Higgins et al, ${ }^{1}$ assessing the distribution of PEF variability in a population sample, requested two hourly PEF readings and used on average seven readings per day. Lee et $a l,{ }^{2}$ surveying the diurnal variation in PEF among polyvinyl chloride workers, used six readings per day. Hetzel et $a l,{ }^{3}$ looking at diurnal variation in normal and asthmatic subjects, used four readings per day while Revsbech et $a l,{ }^{4}$ studying diurnal variation in PEF among grain elevator workers used three readings per day. Quackenboss et $a l,{ }^{5}$ in a study of the normal range of diurnal variation in PEF, used 2-4 readings per day, having requested four readings per day. Many commercial therapeutic trials use two readings per day.

Few studies have looked at the effect of using different numbers of $\mathrm{PEF}$ readings on calculating diurnal variation. D'Alonzo et al compared four evenly spaced PEF readings, or two PEF 


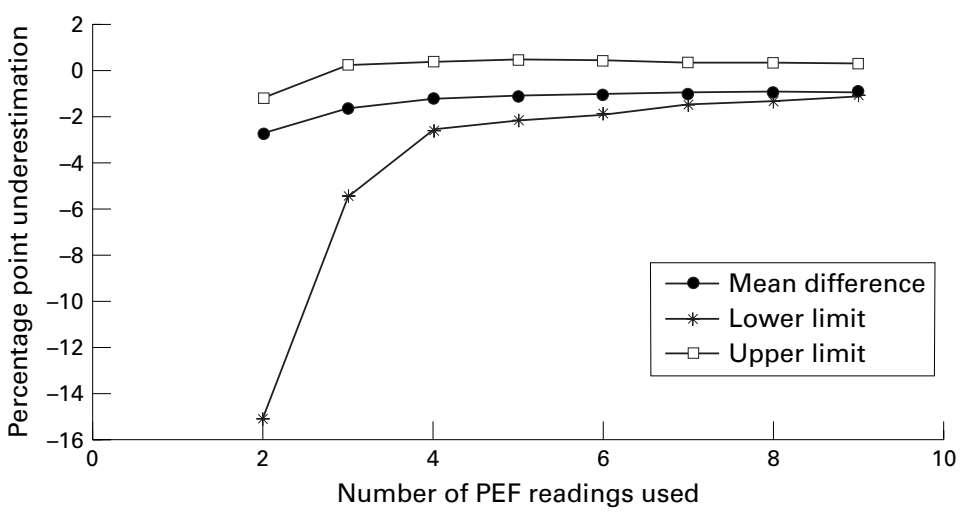

Figure 1. Mean underestimate of true diurnal variation and limits of possible underestimates by number of evenly spaced PEF readings used.

readings taken on rising and 12 hours later, with 13 two hourly PEF readings taken over a 24 hour period. They found that when only two readings were used variability was grossly underestimated with only $20-45 \%$ of actual variability being detected compared with 60 $80 \%$ when four evenly spaced readings were used, which was thought to be clinically acceptable.

Malo et al addressed this question specifically in relation to the investigation of occupational asthma and found that interpretation of PEF readings taken every two hours had two advantages over less frequent readings: (1) greater agreement among three readers as to the diagnosis and (2) a greater concordance in terms of diagnostic sensitivity and specificity compared with the results of specific bronchial challenge testing.

Thus there is no general consensus as to the number of readings required to assess diurnal variation accurately in either clinical practice or pharmaceutical study. This study was designed to determine the number of PEF readings

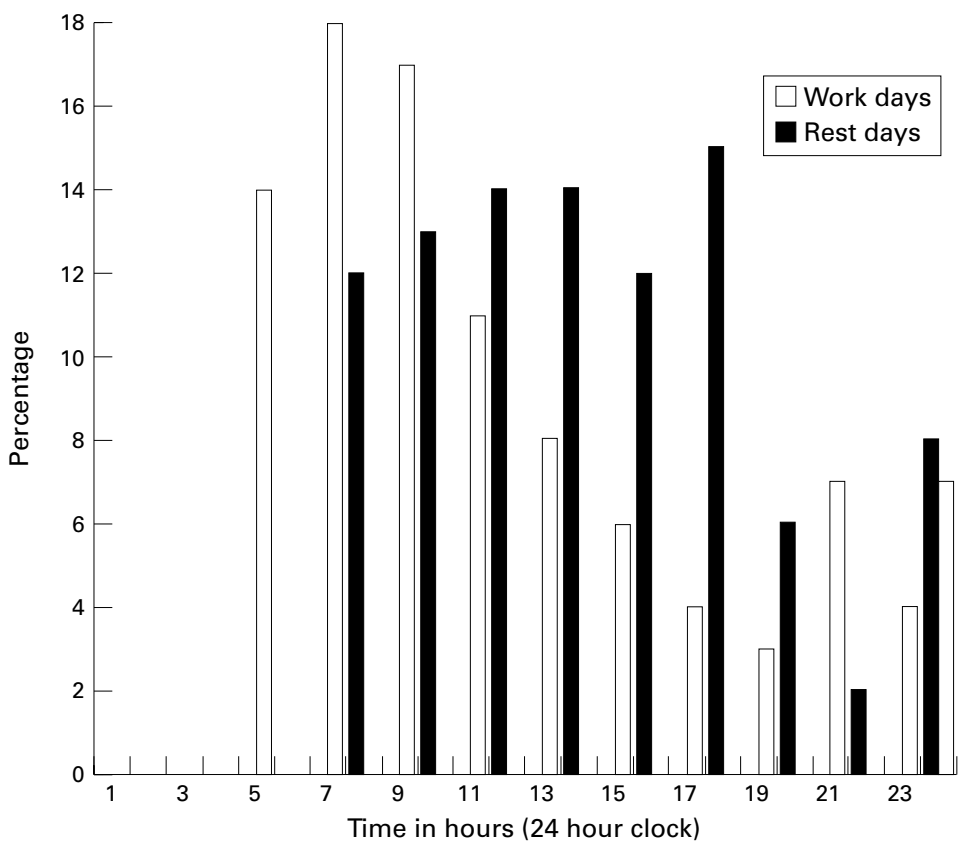

Figure 2 Frequency distribution of the timing of the highest daily PEF reading. Work days (unshaded) and rest days (shaded) are shown. The timing of the highest reading is earlier on work days which may be related to the earlier waking time. required per day to assess diurnal variation accurately.

\section{Methods}

PEF records were obtained from workers performing two hourly PEF readings for the investigation of possible occupational asthma. PEF readings were requested two hourly between waking and sleeping. The readings were taken prior to regular or as required bronchodilator treatment. All days with 10 self recorded PEF readings were selected from a database of PEF records. Diurnal variation for each day was calculated using between two and 10 of the PEF readings. Diurnal variation calculated using all 10 readings was taken as the true diurnal variation. When fewer than 10 readings were used these were evenly spaced over waking hours (table 1). Diurnal variation was calculated as maximum - minimum/ predicted.

Diurnal variations calculated using 2-9 of the available readings were compared with that calculated using the full 10 PEF readings for agreement using the statistical method described by Bland and Altman. ${ }^{8}$ This method can be used to assess agreement between two methods of clinical measurement-in this case diurnal variation calculated using $10 \mathrm{PEF}$ readings per day and that using $2-9$ readings per day. It calculates limits of agreement based on the mean difference and the standard deviation of the differences. Log transformation was undertaken prior to analysis due to the relationship between the difference in diurnal variation and the level of diurnal variationthat is, the difference in diurnal variation calculated using the two methods was likely to be greater with higher actual diurnal variation.

Analysis of the timing of the highest PEF reading of the day was undertaken for rest and work days to determine whether two or three carefully timed PEF readings per day could be used to capture the true diurnal variation.

\section{Results}

Two hundred and twenty five days with $10 \mathrm{PEF}$ readings were selected from PEF records provided by 63 individuals ( $73 \%$ men) of mean age 41 (range 18-66) years, $83 \%$ days at work ( $5 \%$ night shift). Mean underestimates of diurnal variation calculated using less than 10 readings per day and limits of possible underestimates of diurnal variation are shown in table 1 and this information is graphically represented in fig 1 .

When two evenly spaced PEF readings were used to calculate diurnal variation the mean underestimate of true diurnal variation was 2.80 percentage points; the limits of agreement suggest a possible underestimates of 1.2315.10 percentage points. When four evenly spaced PEF readings were used the mean underestimate of true diurnal variation was 1.30 percentage points with a possible underestimate of $0.27-3.96$ percentage points. Mean underestimates and limits of possible underestimation continue to fall above four evenly spaced readings per day, but at a less impressive 
rate than between two and four readings per day (fig 1).

Analysis of the timing of the highest PEF reading of the day was undertaken for rest and work days and showed a mean (SD) timing of 13:56 (4:56) hours for rest days and 11:47 $(5: 59)$ hours for work days. A frequency distribution of the highest daily PEF reading is shown in fig 2 .

\section{Discussion}

Although the PEF readings in this study were collected from workers under investigation for occupational asthma, the results should be applicable to a general population attending an asthma clinic. Possible confounding factors such as night work are present in only a small number of PEF records studied and are unlikely to have affected the overall results. All participants were of working age and were working. This may have influenced their ability to perform large numbers of PEF readings per day but their diurnal variation should have been the same as a non-working population, with the exception of workers who have significant allergic reactions to sensitising agents. The excess of male workers should not have influenced the results.

These results suggest that clinically significant underestimates of true diurnal variation may be seen when only small numbers of PEF readings per day are used in its calculation. In keeping with the work of D'Alonzo et al in which four or more readings were used, the underestimate becomes increasingly insignificant.

In the results we have quantified the information lost in the underestimate of diurnal variation as a reduction of percentage points of diurnal variation calculated as maximum - minimum/predicted PEF. This may have served to reduce the apparent loss of variation compared with expressing the actual underestimate of PEF variation in absolute terms expressed as a percentage of the true absolute variation in litres per minute. This may have influenced our choice of the optimum number of PEF readings required to accurately assess PEF.

It is possible theoretically to capture the true diurnal variation with fewer than four readings by carefully choosing the timing of the readings to capture the predicted early morning trough and afternoon peak in PEF. However, as the afternoon peak has been shown to exhibit individual variation, ${ }^{9}$ and in our study showed a wide variation of timing around the mean peak of 14.00 hours on rest days with an earlier peak at 11.47 hours on working days, it is unlikely to be captured consistently with just two or three PEF readings per day. The earlier timing of the highest PEF reading on days at work may be related to the usual earlier waking time on those days.

It is also theoretically possible to capture most diurnal variation by performing a PEF reading before bronchodilators on waking and one following bronchodilators during the afternoon. However, this is likely to confuse the picture when dealing with allergic asthma or work related asthma, when the afternoon may be the timing of allergic asthmatic reactions.

The number of PEF readings required to capture the true diurnal variation is also likely to be influenced by the degree of diurnal variation exhibited by a patient, the higher the diurnal variation the greater the number of PEF readings required to assess the variation accurately.

In conclusion, the authors suggest that at least four evenly spaced PEF readings per day should be performed to obtain an accurate assessment of diurnal variation in PEF.

1 Higgins BG, Britton JR, Chinn S, et al. The distribution of peak expiratory flow variability in a population sample. $\mathrm{Am}$ peak expiratory flow variability in a
Rev Respir Dis 1989;140:1368-72.

2 Lee HS, Ng TP, Phoon WH. Diurnal variation in peak expiratory flow among polyvinylchloride workers. $\mathrm{Br} \mathcal{F}$ Ind Med 1991;48:275-8.

3 Hetzel MR, Clark TJH. Comparison of normal and asthmatic circadian rhythms in peak expiratory flow rate. Thorax 1980;35:732-8.

4 Revsbech P, Andersen G. Diurnal variation in peak expiratory flow among grain elevator workers. $\mathrm{Br} F$ Ind $\mathrm{Med}$ 1989;46:566-9.

5 Quackenboss JJ, Lebowitz MD, Krzyzanowski M. The normal range of diurnal changes in peak expiratory flow rates. Relationship to symptoms and respiratory disease. Am Rev Respir Dis 1991;143:323-30.

6 D'Alonzo GE, Volker WS, Keller A. Measurements of morning and evening airflow grossly underestimate the circadian variability of $\mathrm{FEV}_{1}$ and peak expiratory flow rate in asthma. Am f Respir Crit Care Med 1995;152:1097-9.

7 Malo JL, Cote J, Cartier A, et al. How many times per day shoulf peak expiratory flow rates be assessed when investigating occupational asthma. Thorax 1993;48:1211-7.

8 Bland JM, Altman DG. Statistical methods for assessing agreement between two methods of clinical measurement. Lancet $1986 ; \mathrm{i}: 307-10$

9 Randem B, Smolensky MH, Hsi B, et al. Field survey of circadian rhythm in PEF of electronics workers suffering from colophony-induced asthma. Chronobiology Int 1987;4:263- 